\title{
Ice crystal properties of amber ice and strain enhancement at the base of cold Antarctic glaciers
}

\author{
Denis SAMYN, ${ }^{1}$ Anders SVENSSON, ${ }^{2}$ Sean J. FITZSIMONS, ${ }^{3}$ Reginald D. LORRAIN ${ }^{1}$ \\ ${ }^{1}$ Département des Sciences de la Terre et de l'Environnement, Faculté des Sciences, CP 160/03, Université Libre de Bruxelles, \\ B-1050 Brussels, Belgium \\ E-mail: desamyn@ulb.ac.be \\ ${ }^{2}$ The Niels Bohr Institute, Blegdamsvej 17, DK-2100 Copenhagen, Denmark \\ ${ }^{3}$ Department of Geography, University of Otago, PO Box 56, Dunedin, New Zealand
}

\begin{abstract}
To improve our understanding of the deformation properties of cold-based polar glaciers, we examine here some of the factors leading to the localization of strain within the amber ice facies. We present a crystallographic case study of amber ice (a fine-grained bubbly ice containing a relatively high impurity content) sampled at the base of two Antarctic glaciers. The crystal fabrics and textures of amber ice were computed by application of a recently developed automated method. To date, it was tedious and awkward to determine amber ice facies accurately because of the sub-millimetric crystal size and relatively high debris content of this facies. The authomatic analytical method applied in this study allows not only for improving analytical accuracy in this task but also for considerably reducing the time of analysis. Our investigations reveal highly homogeneous crystallographic properties for the studied amber ice. The ice crystals are mainly polygonal, equant and sub-millimetric, and show a strong latticepreferred orientation. These properties, beside the relatively high impurity content, are likely to exert a major control on strain enhancement in amber ice when this facies is present at the base of cold glaciers.
\end{abstract}

\section{INTRODUCTION}

Amber ice was first described by Holdsworth (1974) at the base of Meserve Glacier, Wright Valley, Antarctica. There, the amber ice facies consists of a zone of amber-coloured bubbly ice $0.4-0.6 \mathrm{~m}$ thick. When compared to the clean englacial ice above, the amber ice was found to have a relatively high concentration of salts and dispersed silt-tosand particles, the distribution of these impurities being in addition remarkably uniform. Another striking feature reported by Holdsworth was that amber ice is rheologically much softer than the adjacent basal ice facies. This phenomenon was recently reinvestigated at Meserve Glacier by Cuffey and others $(2000 a, b)$ and observed at the margin of Suess Glacier, Taylor Valley, Antarctica, by Fitzsimons and others (1999, 2001). Here we report detailed structural (basal ice velocity) and petrographical (amber ice fabrics) studies conducted at the base of Suess and Rhone Glaciers, Taylor Valley, that are consistent with the above observations. The potential influences of lattice-preferred orientation (LPO), impurities and intercrystalline liquid water on the localization of strain within amber ice are discussed in relation to the deformation mechanisms that operate within this facies.

\section{FIELD SITES AND METHODS}

Suess and Rhone Glaciers are small cold-based glaciers descending steeply from the Asgard Range in Taylor Valley, Dry Valleys, Antarctica, and flowing on unconsolidated sediments. The terminus of these glaciers forms an 18-20 m high ice cliff overriding an ice-and-debris apron. The terminus of Suess Glacier is damming the perennially frozen Lake Popplewell, whereas the snout of Rhone Glacier does not reach the bottom of the valley (Fig. 1).

The base of both glaciers was excavated by digging a tunnel from the foot of the ice cliff. This was done with the aid of jackhammers and electrical chain-saws equipped with tungsten carbide cutters. The tunnels at Suess and Rhone Glaciers were respectively excavated during the austral summers of 1996/97 (Fitzsimons and others, 1999) and 1999/2000. At the end of these tunnels, a vertical shaft was dug in order to exhume the basal ice sequence and to sample ice blocks. In both tunnels, the basal ice temperature was $-17^{\circ} \mathrm{C}$. At both sites, the amber ice was not in direct contact with the bed; it was interbedded between the clean englacial ice above and an alternation of debris-rich and clean ice layers below.

The basal velocity of Suess and Rhone Glaciers was measured in the terminal shafts with the aid of linear variable displacement transducers and precision dial gauges capable of measuring displacements of $0.01 \mathrm{~mm}$. The distances measured between plumb-lines and wooden pegs drilled into the ice walls of the terminal shafts were also used to characterize the form of the lower part of the

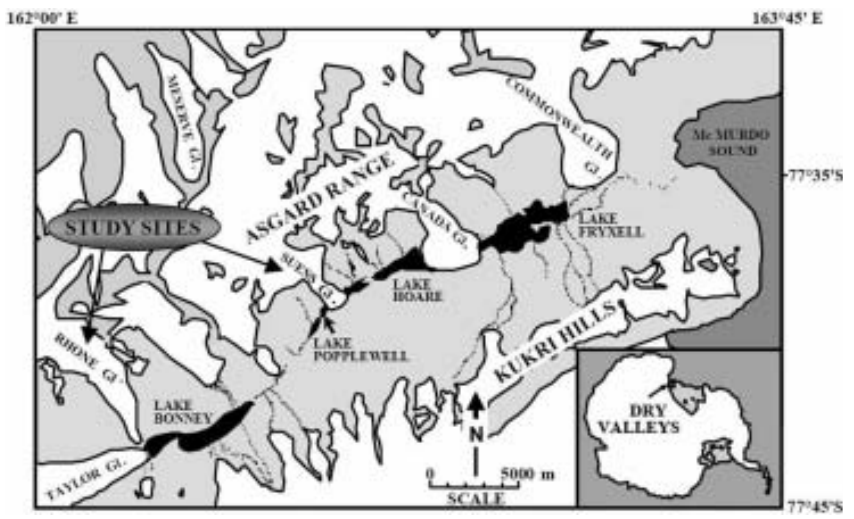

Fig. 1. Map of Taylor Valley, Dry Valleys, South Victoria Land, Antarctica, showing the location of Suess and Rhone Glaciers. 


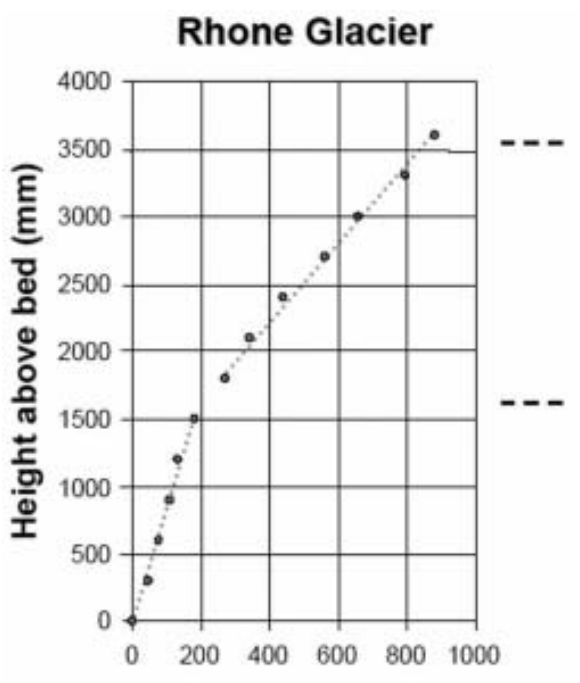

Basal ice velocity $\left(\mathrm{mm} \mathrm{a}^{-1}\right)$

Suess Glacier

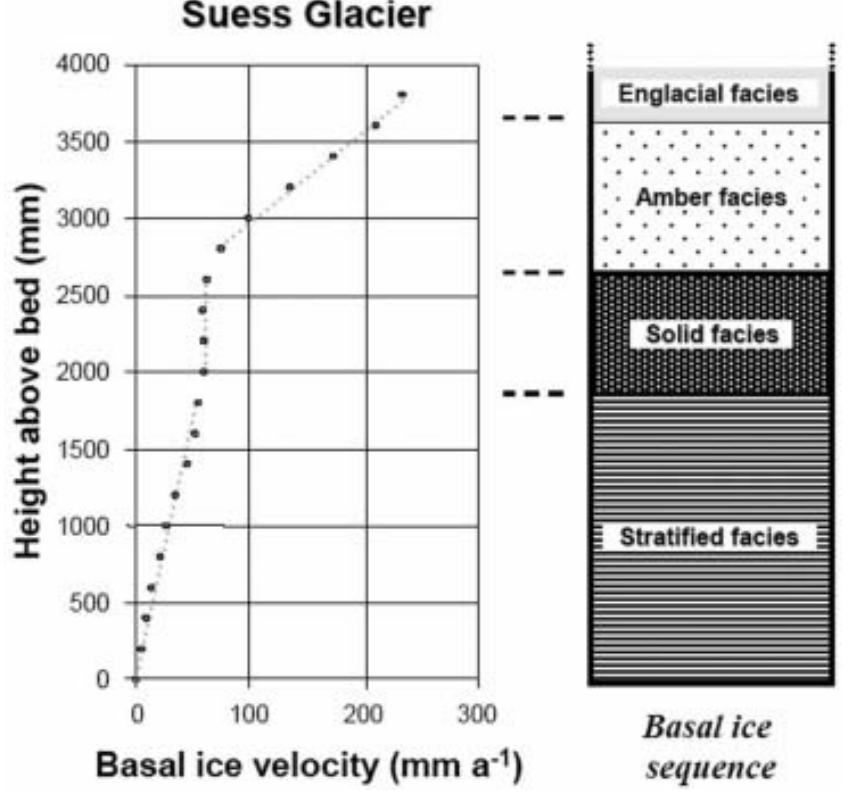

Fig. 2. Velocity profiles within basal ice from Rhone Glacier (this study) and Suess Glacier (after Fitzsimons and others, 1999). Measurements were done using plumb-lines and dial gauges resurveyed after around 1 year.

velocity profile. The whole method for glacier basal velocity measurement was described by Fitzsimons and others (1999).

For analytical purposes, adjoining ice blocks $(30 \times 10 \times$ $20 \mathrm{~cm}^{3}$ ) were retrieved along the vertical from top to bottom of both shafts. After sampling, the ice blocks were wrapped in polyethylene bags, stored at $-18^{\circ} \mathrm{C}$, and transferred to the cold laboratory in Brussels.

In the cold room, vertical thin sections were cut all along the two basal ice profiles. Due to the presence of a high amount of debris, most of the thin sections were cut using a diamond wire saw as described below. Particular attention was paid during the preparation of amber-ice thin sections.

\section{STUDYING THE PETROGRAPHY OF AMBER ICE}

Very few studies of ice fabrics have been published about debris-laden fine-grained ice. This is mainly because of the

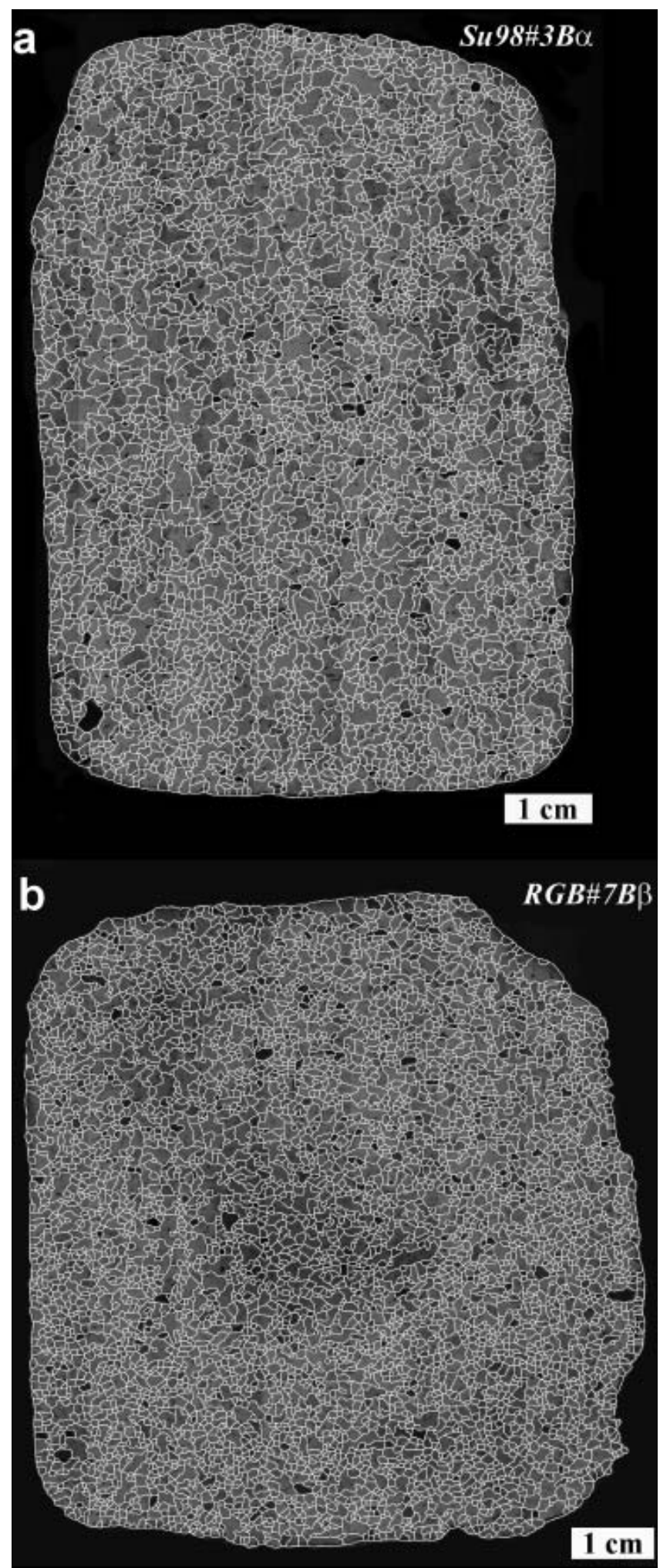

Fig. 3. Representative thin sections of amber ice from (a) Suess and (b) Rhone Glaciers. Artificial greyscale images with crystal contour mask obtained by application of an automated image processing method. The top-bottom direction of the photographs coincides with the vertical.

difficulty of cutting thin sections within such a material without damaging either the cutting equipment or the ice sample itself. Moreover, when the ice is fine-grained, it is awkward not only to identify the crystal angle of extinction, but also to track individual crystals through the multiple 


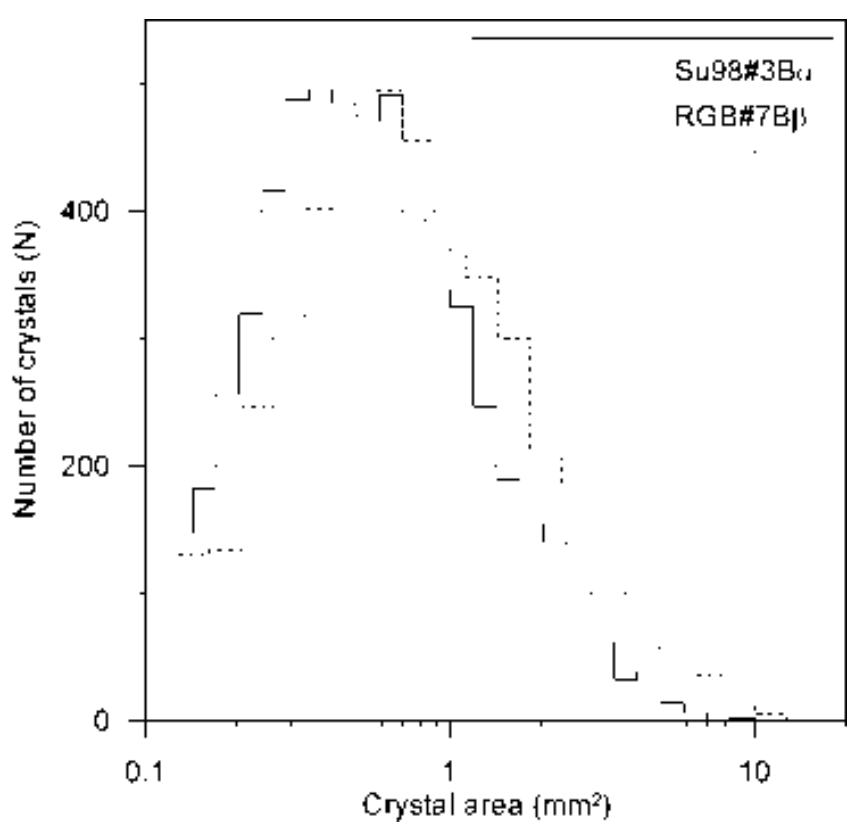

Fig. 4. Crystal area distribution $(N=500)$ for two representative amber-ice thin sections from Suess and Rhone Glaciers. Note the logarithmic scale of the $x$ axis.

rotation steps of the Rigsby stage. In this work, these difficulties were bypassed as follows. In the Université Libre de Bruxelles cold laboratory, thin sections were prepared from amber ice applying the diamond wire-saw cutting technique described by Tison (1994). These sections were then smoothed and thinned with sandpapers of decreasing grit size until a thickness of about 300-400 $\mu \mathrm{m}$ was reached, this latter step being essential to prevent, as far as possible, overlapping of neighbouring crystals during analysis of the sections. The fabrics and textures of the amber ice crystals were determined at the Niels Bohr Institute, Copenhagen, Denmark, by means of an automated $c$-axis analyzer and subsequent digital image processing (based on the Visual Basics and Image Pro softwares) following a procedure adapted from Svensson and others (2003). For each pixel in the sample images, $c$-axis orientations were calculated with an accuracy close to $5^{\circ}$. The boundaries of crystals as small as $0.1 \mathrm{~mm}^{2}$ were identified, but, because optical properties occasionally changed gradually from one crystal into the next instead of defining sharp domains, the crystal boundaries could not always be properly distinguished. The method succeeded, however, for at least $\sim 80 \%$ of all the ice crystals present on the analyzed sections.

\section{RESULTS}

\section{Velocity profiles}

In the shaft dug at the end of Rhone Glacier tunnel, plumblines and dial gauges recorded velocities from around $50 \mathrm{~mm} \mathrm{a}^{-1}$ at $300 \mathrm{~mm}$ above the glacier bed to around $960 \mathrm{~mm} \mathrm{a}^{-1}$ at $3600 \mathrm{~mm}$ above the bed (Fig. 2). Monitoring of the glacier velocity close to the bed indicated the absence of basal sliding during the 50 week measurement period. Velocity measurements obtained at Rhone Glacier can be compared in Figure 2 with those obtained at the base of Suess Glacier by Fitzsimons and others (1999). At both sites, the amber ice facies appears to have the highest displacement rate.

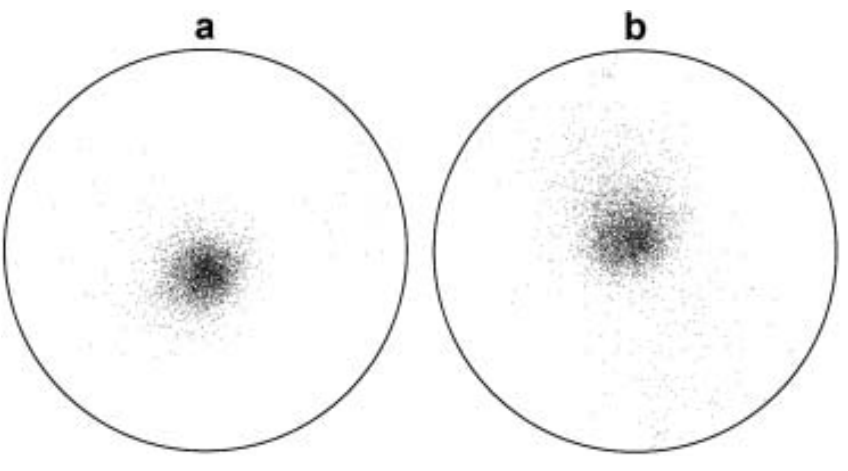

Fig. 5. (a) Fabric pattern for the $S \cup 98 \# 3 B \alpha$ thin section (Suess Glacier). Orientation strength $(R)=95.3 \% ; N=4355$. (b) Fabric pattern for the RGB\#7B $\beta$ thin section (Rhone Glacier). Orientation strength $(R)=90.0 \% ; N=5801$.

\section{Amber ice crystallography}

At both study sites, thin sections cut parallel to the local flow show that the air bubbles enclosed within amber ice are a few millimetres long, with their elongation axis parallel to the ice stratification. Under crossed polarizers, all the amber ice sections, whether cut parallel or normal to the local flow, immediately reveal a highly homogeneous texture. In Figure $3 a$ and $b$, two representative examples of vertical thin sections (Su98\#3B $\alpha$ and $R G B \# 7 B \beta$ ) illustrate this strong homogeneity. The results of crystallographic analyses conducted on these sections are given in Table 1. More than 4000 crystals were inspected on the illustrated sections. The amber ice crystals are mainly equant and sub-millimetric. The crystal size distribution of both sections is very narrow, with little deviation around the mean crystal width and heights on a $\log$ scale (Fig. 4). In Su98 $\# 3 \mathrm{~B} \alpha$, crystals are slightly larger than in RGB\#7B $\beta$. The ice crystals do not present any significant flattening ratio (Table 1). In Figure 5, $c$-axis crystal orientations are represented on equatorial Schmidt diagrams. The degree of crystallographic orientation $(R)$ used here is a parameter that defines the percentage orientation strength. This parameter varies between $0 \%$ for a randomly oriented polycrystal and $100 \%$ for the case when all $c$ axes are exactly parallel (Wallbrecher, 1978). In both sections, the fabric patterns indicate that the $c$-axis orientations are highly homogeneous, with an $R$ parameter reaching a minimum value of 90.0\% (Table 1).

\section{DISCUSSION}

\section{Dislocation creep dominating in amber ice}

When studying the petrography of Meserve Glacier, Anderton (1974) did not obtain any fabric data from amber ice. He noted, however, that the amber ice crystals were likely to have a strong fabric, given the uniform optical behaviour of thin sections examined under crossed polarizers. More recently, Cuffey and others (2000a) also had some difficulty measuring the amber ice crystal fabrics, but obtained successful measurements in $30 \%$ of their attempts by using optical magnifying glasses. The data obtained made Cuffey and colleagues confident that the amber ice fabrics of Meserve Glacier were quite similar to those obtained from the overlying clean ice by Anderton (1974), that is, with a strong single maximum normal to the glacier bed. Our 
Table 1. Crystallographic parameters computed through automatic $c$-axis analysis for representative amber ice sections from two Antarctic cold-based glaciers

\begin{tabular}{|c|c|c|c|c|c|c|c|c|}
\hline Thin-section label & $\begin{array}{l}\text { Height in } \\
\text { the profile } \\
\qquad \mathrm{cm}\end{array}$ & $\begin{array}{c}\text { Mean crystal } \\
\text { width } \\
\text { mm }\end{array}$ & $\begin{array}{c}\text { Mean crystal } \\
\text { height } \\
\text { mm }\end{array}$ & $\begin{array}{c}\text { Mean crystal } \\
\text { area } \\
\mathrm{mm}^{2}\end{array}$ & $\begin{array}{l}\text { Mean crystal } \\
\text { flattening }\end{array}$ & $\begin{array}{l}\text { Mean crystal } \\
\text { roundness }\end{array}$ & $\begin{array}{c}\text { Orientation } \\
\text { strength, } R \\
\%\end{array}$ & $\begin{array}{l}N \text { crystals } \\
\text { measured }\end{array}$ \\
\hline Su98\#3B $\alpha$ (Suess Glacier) & 265 & 1.23 & 1.21 & 1.11 & 1.06 & 1.11 & 95.3 & 4355 \\
\hline RGB\#7B $\beta$ (Rhone Glacier) & 210 & 1.06 & 0.99 & 0.78 & 1.11 & 1.00 & 90.0 & 5801 \\
\hline
\end{tabular}

Note: To approximate three-dimensional crystal dimensions, one should multiply the crystal areas given here by 1.5 and the crystal lengths by $\sqrt{1.5}$ (after Underwood, 1970).

investigations at Suess and Rhone Glaciers also show that the amber ice crystals present a strong LPO perpendicular to the effective glacier bed (Fig. 5). These findings support the predominance of dislocation creep during the strain of amber ice (Azuma, 1994; Duval and others, 2000). We suggest that the building of the observed ice fabrics was initiated by rotation recrystallization, the latter tending to produce a substantial grain-size reduction and to facilitate LPO development through polygonization (e.g. Barber, 1985; Paterson, 1991; Urai and Jessell, 2001).

Strong single-pole fabrics are generally interpreted as reflecting a preferential alignment of the crystal basal planes close to the plane of maximum shear stress (Anderton, 1974; Gow and Williamson, 1976). This idea is supported here by the fact that the orientation of the basal planes coincides with that of the ice foliation, the bubble elongation and the glacier bed, which reveals the influence of strong noncoaxial shearing within amber ice (Anderton, 1974; Gow and Williamson, 1976).

The small size of the amber ice crystals and their favourable orientation for basal glide are likely to play a major role in the high plasticity of this facies, the two latter parameters being considered to partly control strain enhancement (Paterson, 1991; Thorsteinsson and others, 1999; Cuffey and others, 2000b). Russell-Head and Budd (1979), for example, observed through their simple shear tests that ice with a strong single-maximum fabric deformed about four times faster than did isotropic ice. Besides, Baker (1978) reported that, for fine-grained ice, reduction of ice crystal size results in an increase in secondary creep in proportion to about the inverse square of the average grain diameter.

\section{Possible interactions between impurities and ice crystals during amber ice formation}

Crystal size and LPO are not the only factors that can influence the strain rate of ice. Debris type, diameter and concentration are other important parameters to take into account. It is well known from metal and ceramic physics that chemical impurities exert a retarding force (called 'Zener drag' for solutes, and 'pinning' for insoluble impurities) on migrating grain boundaries in a polycrystalline matrix (Alley and others, 1986; Olgaard and Evans, 1986), thereby leading to a decrease in grain-size when impurity content increases (Smith, 1948; Alley and others, 1986; Olgaard and Evans, 1988). Insoluble impurities (or so-called 'second-phase particles' in mineralogy) can furthermore constitute impenetrable obstacles for dislocation movements (Gottstein and Mecking, 1985). Grain growth retardation by chemical impurities has consequently been proposed as potentially controlling the final grain-size achieved during ice recrystallization (Baker, 1978; Alley and others, 1986; Langway and others, 1988), and even helping the strengthening of ice LPO (Langway and others, 1988; Paterson, 1991). The volume fraction of sediments reaches a few per cent within amber ice (Holdsworth, 1974; Cuffey and others, 2000a; Fitzsimons and others, 2001), which has been shown to be sufficient for grain growth retardation to initiate in polycrystalline materials (Alley and others, 1986; Olgaard and Evans, 1986). Inhibition of grain-boundary migration by impurities may thus affect the grain-size, and therefore the strain rate, of amber ice.

Moreover, chemical impurities, whether soluble or insoluble, favour the growth of interfacial liquid films by depressing the pressure-melting point of the ice at the contact interface (e.g. Gilpin, 1979; Dash and others, 1995), thereby increasing the liquid water content. In creep dominated by dislocation motion, these thin liquid films are assumed to increase the activity of the easiest intracrystalline slip system by reducing internal stresses at grain boundaries (De La Chapelle and others, 1999), thereby promoting strain enhancement within the ice. Grain-boundary sliding (GBS) is a grain-size-sensitive deformation mechanism that requires the existence of interstitial fluids (e.g. Zhang and others, 1994). The presence of impurities at grain boundaries should facilitate such a mechanism (Barnes and others, 1971), even at the low temperatures encountered at the base of the studied glaciers (Cuffey and others, 2000a). GBS is, however, believed to be LPO-destructive (e.g. Zhang and others, 1994); its occurrence should thus be limited, given the strong LPO of amber ice crystals. Grain-boundary diffusion (GBD) is another grain-size-sensitive deformation mechanism; it refers to the movement of lattice defects along grain boundaries. This process is unlikely to produce any LPO comparable to the one observed in this study (Pimienta and Duval, 1987), but it should not be LPO-destructive either (e.g. Krabbendam and others, 2003). Therefore, its influence on the strain of amber ice, if effective, would not be distinguishable from a $c$-axis orientation point of view. GBD might, however, have provided another active accommodation mechanism, since it is likely to operate at low temperatures (Duval and others, 1983) as well as at high interstitial impurity concentrations (e.g. Cooper and Kohlstedt, 1986; Dash and others, 1995). To sum up, impurities present in amber ice may not only have influenced the mobility of grain boundaries during recrystallization, but also have determined the mechanisms by which incompatible deformation was accommodated. 


\section{CONCLUSION}

Thanks to a new method and device, crystal fabrics and textures were successfully determined in amber ice, a finegrained and debris-bearing type of ice that represents an important component of some cold-based glaciers from the Dry Valleys, Antarctica.

Our work sheds light on results obtained from previous strain measurements indicating that amber ice strains more rapidly, and is thus rheologically softer, than other basal ice facies. This paper shows that:

1. The displacement rates measured in amber ice are by far the highest from all the ice facies present at the base of the studied glaciers. Amber ice thus accommodates most of the basal deformation and acts in this way as a decoupling horizon between bulk glacier ice and the base of the glacier. This might lead to the relative preservation of adjacent basal ice units.

2. A strong LPO has developed in amber ice from Suess and Rhone Glaciers owing to a reorientation of basal planes perpendicularly to the effective bed during ductile deformation. This provides evidence that deformation was dominated by dislocation motion.

3. In case debris would have effectively taken part in the hindering of grain growth, its presence apparently did not lead to a switch of deformation mechanism from grain-size-insensitive to grain-size-sensitive dominated flow. Debris may, however, have driven the retardation of grain-boundary migration until an equilibrium grain-size was achieved. This grain-size would have then been maintained at a steady state by continual and dynamic recrystallization.

4. The degree to which dislocation creep was aided by the presence of intercrystalline liquid films remains unclear. Given the relatively high impurity content of amber ice, lubrication at the grain boundaries is a possible accommodation mechanism, especially for crystals smaller than the average since interstitial lubrication is likely to be grain-size-sensitive. Having shown that deformation is dominated by dislocation creep in amber ice, we strongly support the idea of De La Chapelle and others (1999) that the liquid phase would have the effect of increasing the activity of the easiest slip system by reducing the peaks of internal stress at grain boundaries.

Further work needs to be done in order, first, to identify which of the textural and structural crystal parameters are the most influential upon deformation of amber ice, and, second, to determine in what proportion mass transfer along the intercrystalline liquid network may help to accommodate strain incompatibilities at grain-boundary scale. Such work could help to resolve the discrepancy of results and conclusions relative to the origin of strain partitioning within basal ice.

\section{ACKNOWLEDGEMENTS}

This paper is a contribution to the Belgian Antarctic Program (Science Policy Office). We thank Antarctica New Zealand for providing the logistical support of this study, and the Marsden Fund of the Royal Society of New Zealand as well as the University of Otago for financial support. D. Samyn acknowledges support of a grant from Fonds pour la Formation à la Recherche dans I'Industrie et dans I'Agriculture (Belgium).

\section{REFERENCES}

Alley, R.B., J.H. Perepezko and C.R. Bentley. 1986. Grain growth in polar ice: II. Application. J. Glaciol., 32(112), 425-433.

Anderton, P.W. 1974. Ice fabrics and petrography, Meserve Glacier, Antarctica. J. Glaciol., 13(68), 285-306.

Azuma, N. 1994. A flow law for anisotroic ice and its application to ice sheets. Earth Planet Sci. Lett., 128(3-4), 601-614.

Baker, R.W. 1978. The influence of ice-crystal size on creep. J. Glaciol., 21(85), 485-500.

Barber, D.J. 1985. Dislocations and microstructures. In Wenk, H.R., ed. Preferred orientation in deformed metals and rocks: an introduction to texture analysis. London, Academic Press, 183-218.

Barnes, P., D. Tabor and J.C.F. Walker. 1971. The friction and creep of polycrystalline ice. Proc. R. Soc. London, A125, 670-693.

Beaglehole, D. and P. Wilson. 1994. Extrinsic premelting at the iceglass interface. J. Phys. Chem., 98(33), 8096-8100.

Cooper, R.F. and D.L. Kohlstedt. 1986. Rheology and structure of olivine-basalt partial melts. J. Geophys. Res., 91(B9), 9315-9323.

Cuffey, K.M., H. Conway, A. Gades, B. Hallet, C.F. Raymond and S. Whitlow. 2000a. Deformation properties of subfreezing glacier ice: role of crystal size, chemical impurities, and rock particles inferred from in situ measurements. J. Geophys. Res., 105(B12), 27,895-27,915.

Cuffey, K.M., T. Thorsteinsson and E.D. Waddington. 2000b. A renewed argument for crystal size control of ice sheet strain rates. J. Geophys. Res., 105(B12), 27,889-27,894.

Dash, J.G., H.Y. Fu and J.S. Wettlaufer. 1995. The premelting of ice and its environmental consequences. Rep. Prog. Phys., 58(1), 115-166.

De La Chapelle, S., H. Milsch, O. Castelnau and P. Duval. 1999. Compressive creep of ice containing a liquid intergranular phase: rate-controlling processes in the dislocation creep regime. Geophys. Res. Lett., 26(2), 251-254.

Duval, P., M.F. Ashby and I. Anderman. 1983. Rate-controlling processes in the creep of polycrystalline ice. J. Phys. Chem., 87(21), 4066-4074.

Duval, P., L. Arnaud, O. Brissaud, M. Montagnat and S. De La Chapelle. 2000. Deformation and recrystallization processes of ice from polar ice sheets. Ann. Glaciol., 30, 83-87.

Fitzsimons, S.J., K.J. McManus and R.D. Lorrain. 1999. Structure and strength of basal ice and substrate of a dry-based glacier: evidence for substrate deformation at sub-freezing temperatures. Ann. Glaciol., 28, 236-240.

Fitzsimons, S.J., K.J. McManus, P. Sirota and R.D. Lorrain. 2001. Direct shear tests of materials from a cold glacier: implications for landform development. Quat. Int., 86(1), 129-137.

Gilpin, R.R. 1979. A model of the 'liquid-like' layer between ice and a substrate with applications to wire regelation and particle migration. J. Colloid Interface Sci., 68(2), 235-251.

Gottstein, G. and H. Mecking. 1985. Recrystallisation. In Wenk, H.R., ed. Preferred orientation in deformed metals and rocks: an introduction to modern texture analysis. London, Academic Press, 183-218.

Gow, A.J. and T. Williamson. 1976. Rheological implications of the internal structure and crystal fabrics of the West Antarctic ice sheet as revealed by deep core drilling at Byrd Station. CRREL Rep. 76-35.

Holdsworth, G. 1974. Meserve Glacier, Wright Valley, Antarctica: Part 1. Basal processes. Ohio State University, Columbus, Ohio, Institute of Polar Studies Report 37, 1-104.

Krabbendam, M., J.L. Urai and L.J. van Vliet. 2003. Grain size stabilisation by dispersed graphite in a high-grade quartz mylonite: an example from Naxos (Greece). J. Struct. Geol., 25(6), 855-866. 
Langway, C.C., Jr, H. Shoji and N. Azuma. 1988. Crystal size and orientation patterns in the Wisconsin-age ice from Dye 3, Greenland. Ann. Glaciol., 10, 109-115.

Olgaard, D.L. and B. Evans. 1986. Effect of 2nd-phase particles on grain-growth in calcite. J. Am. Ceramic Soc., 69(11), C272-C277.

Olgaard, D.L. and B. Evans. 1988. Grain growth in synthetic marbles with added mica and water. Contrib. Mineral. Petrol., $\mathbf{1 0 0}(2)$, 246-260.

Paterson, W.S.B. 1991. Why ice-age ice is sometimes 'soft'. Cold Reg. Sci. Technol., 20(1), 75-98.

Pimienta, P. and P. Duval. 1987. Rate controlling processes in the creep of polar glacier ice. J. Phys. (Paris), 48, Colloq. C1, 243248. (Supplément au 3.)

Russell-Head, D.S. and W.F. Budd. 1979. Ice-sheet flow properties derived from bore-hole shear measurements combined with icecore studies. J. Glaciol., 24(90), 117-130.

Smith, C.S. 1948. Grains, phases, and interfaces: an interpretation of microstructure. Trans. Metall. Soc. AIME, 175, 15-51.

Svensson, A. and 6 others. 2003. Properties of ice crystals in North GRIP late- to middle-Holocene ice. Ann. Glaciol., 37, 113-118.
Thorsteinsson, T., E.D. Waddington, K.C. Taylor, R.B. Alley and D.D. Blankenship. 1999. Strain-rate enhancement at Dye 3, Greenland. J. Glaciol., 45(150), 338-345.

Tison, J.L. 1994. Diamond wire-saw cutting technique for investigating textures and fabrics of debris-laden ice and brittle ice. J. Glaciol., 40(135), 410-414.

Underwood, E.E. 1970. Quantitative stereology. Reading, MA, Addison-Wesley Publishing.

Urai, J.L. and M.W. Jessell. 2001. Recrystallisation and grain growth in minerals: recent developments. In Gottstein, G. and D.A. Molodov, eds. Recrystallisation and Grain Growth, Proceedings of the First Joint International Conference, August 27-31, 2001. RWTH Aachen, Germany. Berlin, Springer Verlag, 87-96.

Wallbrecher, E. 1978. Ein Cluster-Verfahren zur richtungsstatistischen Analyse tektonischer Daten. Geol. Rundsch., 67, 840-857.

Zhang, Y., B.E. Hobbs and M.W. Jessell. 1994. The effect of grain boundary sliding on fabric development in polycrystalline aggregates. J. Struct. Geol., 16(9), 1315-1326. 